\title{
PRIMARY SHIELDING CALCULATIONS \\ ON THE IBM 650 (ROC CODES)
}

CONTRACT NO. AT(30-3) -326

Issued October 15, 1958

By

S. B. Rosen
P. V. Oby
R. L. Caton

Alco Products, Inc. Post Office Box 414 Schenectady 5, N. Y. 


\section{DISCLAIMER}

This report was prepared as an account of work sponsored by an agency of the United States Government. Neither the United States Government nor any agency Thereof, nor any of their employees, makes any warranty, express or implied, or assumes any legal liability or responsibility for the accuracy, completeness, or usefulness of any information, apparatus, product, or process disclosed, or represents that its use would not infringe privately owned rights. Reference herein to any specific commercial product, process, or service by trade name, trademark, manufacturer, or otherwise does not necessarily constitute or imply its endorsement, recommendation, or favoring by the United States Government or any agency thereof. The views and opinions of authors expressed herein do not necessarily state or reflect those of the United States Government or any agency thereof. 


\section{DISCLAIMER}

Portions of this document may be illegible in electronic image products. Images are produced from the best available original document. 
I INTRODUCTION ....................... 1

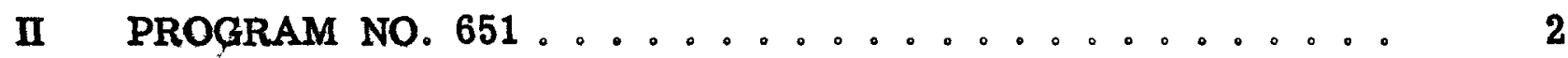

II-1 Description .................... 2

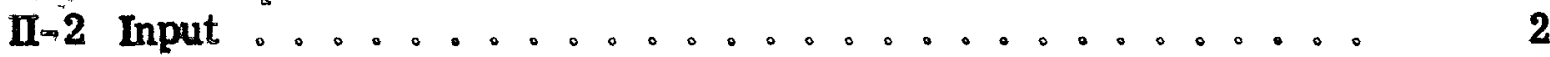

II -3 Output $\ldots \ldots \ldots \ldots$

II-4 Timing ....................... 4

III PROGRAM NO. $652 \ldots \ldots \ldots \ldots \ldots \ldots$

III-1 Description ................... 4

$\mathrm{III}-2$ Input . ..................... 5

III-3 Output ....................... 7

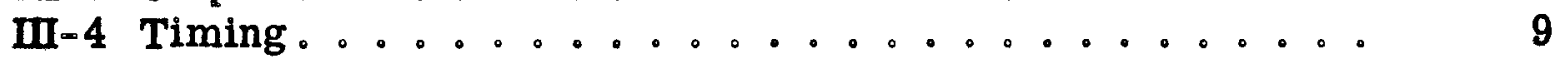

IV PROGRAM NO. $653 \ldots \ldots \ldots \ldots \ldots$

IV-1 Description .................... 9

IV - 2 Input . . . . . . . . ............ 10

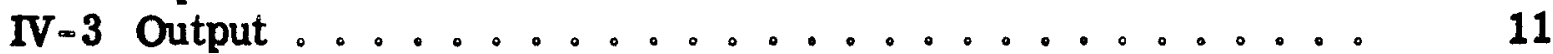

IV-4 Timing . . . . . . . .............. 12

V PROGRAM NO. $654 \ldots \ldots \ldots \ldots \ldots$

$\mathrm{V}-1$ Description.................... 12

$V-2$ Input $\ldots \ldots \ldots \ldots 14$

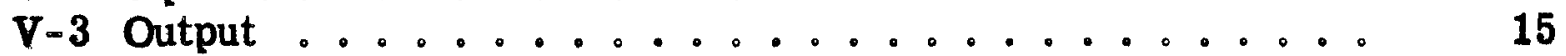

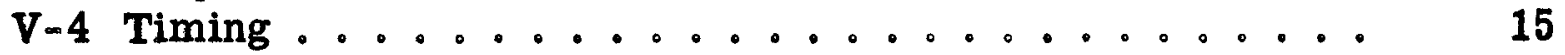

VI MACHINE OPERATION (ALL PROGRAMS) . . . . . . . 16

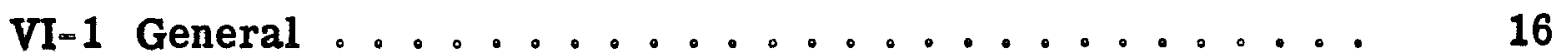

VI-2 Input Deck Make-up ................. 16

VI-3 Machine Stops .................... 18

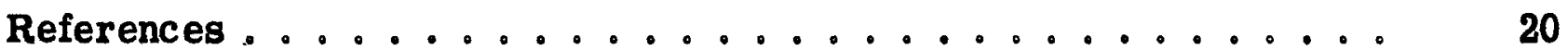

Appendices

Appendix A: Program 651 Files ..............

Appendix B: Program 652 Files .............

Appendix C: Programs 653 and 654 Files ..........

Appendix D: Floating Point Representation . . . . . . . .

Appendix E: Flow Charts . . . . . . . . . . . . 


\section{DISTRIBUTION}

COPY

1-2

New York Operations Office

U. S. Atomic Energy Commission

70 Columbus Avenue

New York 23, New York

ATTENTION: Capt.Richard L. Harris

(V. J. Del Vecchia for C)

$3-4$

U. S. Atomic Energy Commission

Washington 25, D.C.

ATTENTION: Classified Technical Library for Col. D. G. Williams

U. S. Atomic Energy Commission

Army Reactors Branch

Division of Reactor Development

Washington 25, D. C.

ATtention: Major Paul H. Ugis

8

U. S. Atomic Energy Commission

Chief, Patents Branch

Washington 25, D. C.

ATTENTION: Roland A. Anderson

U. S. Atomic Energy Commission

Chicago Operations Office

P. O. Box 59

Lemont, Illinois

ATTENTION: Captain J. Schweizer 
COPY

10

U. S. Atomic Energy Commission

Idaho Operations Office

Phillips Petroleum Company, NRTS

Technical Library

P. O. Box 1250

Idaho Falls, Idaho

ATTENTION: Major Robert L。Ednie

11

Nuclear Power Field Office

USERDL

Fort Belvoir, Virginia

ATTENTION: Major W。R。Wray

12

Union Carbide Nuclear Corporation

Oak Ridge National Laboratory

Y-12 Building 9704-1

P. O. Box "Y"

Oak Ridge, Tennessee

ATTENTION: A. L。Boch

13

District Engineer, Alaska District

U. S. Army Corps of Engineers

P. O. Box 1288

Anchorage, Alaska

ATTENTION: NPAVG-N

14

The Martin Company

P. O. Box 5042

Middle River, Maryland

ATTENTION: AEC Contract Document Custodian 
COPY

15-39

and

Multi -

lith

Masters

$40-41$

$42-59$
U. S. Atomic Energy Commission Reference Branch

Technical Information Services Extension P. O. Box 62

Oak Ridge, Tennessee

Alco Products, Inc.

P. O. Box 145

Ft. Belvoir, Virginia

ATTENTION: H. L. Weinberg

Alco Products, Inc.

P. O. Box 414

Schenectady, N. Y.

K. Kasschau

J. G. Gallagher

S. S. Rosen

S. D. Mackay

J. T. Lence (ASTRA)

E. M. Reiback

M. J. Leibson
B. J. Byrne

P. V. Oby

R. O. Bagley

P. E. Bobe

R. J. Clark

W. S. Brown

File-5 


\section{INTRODUCTION}

In order to calculate the gamma dose rates in the primary shielding of thermal reactors, four programs were written for the IBM 650 computer. The background material for these calculations is found in the table of references. The shielding programs had their inception as a result of the study reported in reference (5),

The four programs or codes are numbered 651 through 654 . Their functions are outlined as follows:

1. Program 651 - calculates the core attenuation coefficient and equivalent core gamma volumetric source values for a specified core.

2. Program 652 - calculates the activation gamma source data in the shield and prepares tabular data in machine storage for Programs 653 and 654.

3. Program 653 - calculates the gamma dose rates in the shield due to gamma arising from activation of shield materials.

4. Program 654 - calculates the gamma dose rates in the shield due to gammas arising in the core.

Gamma photon source values are obtained on the basis of two group neutron flux distributions throughout the reactor core and shield.

Basic input information consists primarily of material and geometry data plus normalized two group neutron flux values. Output consists of five different energy groups of dose rates due to five distinct gamma groups.

A comparison of results obtained from machine calculations and experimental results is given in reference (5).

The calculation of gamma heating rates in the primary shielding may also be calculated using the $65 \mathrm{X}$ series of codes. The following write-ups are still applicable; the only changes lie in the values appearing in the material energy files. Values for these files are in the process of compilation.

Another application of these codes is in the consideration of demineralizer shielding. The treatment of this problem will be given in a separate report.

Other applications are of course possible and the equations and mechanisms of these codes should be kept in mind in this regard. 


\section{II-1 Description}

Program 651 calculates the average core attenuation coefficient, and the average core gamma source strength, $S_{c}$, for each of five energy groups. Results are punched out on five cards to be used with Program 654.

The equations programmed for the 650 are -

$$
\begin{aligned}
& \mu_{s}=\sum_{m} V_{m} \mu_{m} \\
& S_{m}\left\{V_{m} \Phi_{s} F_{m}+V_{m} \phi_{f} G_{m}\right\}
\end{aligned}
$$

where $\mu_{s}=$ core attenuation coefficient $-\mathrm{cm}^{-1}$

$\mathrm{V}_{m}=$ volume fraction of material $\mathrm{m}$ in the core

$\mu_{m}=$ attenuation coefficient for material $\mathrm{m}-\mathrm{cm}^{-1}$

$\mathrm{S}_{c}=$ core source strength - photons $/ \mathrm{cm}^{3} \mathrm{sec}$

$\bar{\phi}=$ average slow flux in the core - neutrons $/ \mathrm{cm}^{2} \mathrm{sec}$

क average fast flux in the core - neutrons $/ \mathrm{cm}^{2} \mathrm{sec}$

$\mathbf{F}_{m}=$ core gamma parameters for slow neutrons - see (1)

$\mathrm{G}_{m}=$ core gamma parameters for fast neutrons - see (1)

\section{II-2 Input}

Necessary input for Program 651 consists of a Type 01 card, a Type 02 card, material specifications and a time after shutdown specification. The last two are used to select material energy files. The form of the various cards are as follows:

1. Type 01 card

Col $\begin{array}{rl}1-10 & 651 \text { PPPP001 } \\ 11-20 & \mathrm{~V}_{\mathrm{m}} \text { of } \mathrm{U}^{25} \text { or } \mathrm{U}^{25} \mathrm{O}_{2} \\ 21-30 & \mathrm{~V}_{\mathrm{m}} \text { of } \mathrm{U}^{28} \text { or } \mathrm{U}^{28} 0_{2} \\ 31-40 & \mathrm{~V}_{\mathrm{m}} \text { of } 304 \mathrm{SS} \\ 41-50 & \mathrm{~V}_{\mathrm{m}} \text { of } \mathrm{H}_{2}^{\prime} 0 \\ 51-60 & \mathrm{~V}_{\mathrm{m}} \text { of } \mathrm{C} \\ 61-70 & \mathrm{~V}_{\mathrm{m}} \text { of } \mathrm{Th}^{232} \\ 71-80 & \text { Zeros }\end{array}$


Col $1-10 \quad 651$ PPPP002

$11-20$

21-30

31-80 Blank

For both Type 01 and Type 02 cards, PPPP is a case number to be assigned by the user. These numbers need not be the same; however, identification on the output is taken from the Type 02 card.

Values of the volume fractions and the fluxes must be entered in floating point form. For a discussion of floating point forms, see Appendix D.

3. Material Energy File Cards

$7 \mathrm{req}^{\prime} \mathrm{d} /$ energy

$\begin{array}{rll}\text { Co1 } & 1-10 & 07 \text { LLLL0004 } \\ 11-20 & F_{m} \\ 21-30 & G_{m} \\ 31-50 & \text { Zeros } \\ 51-60 & \text { Blank } \\ 61-70 & \text { Material Name } \\ 71-80 & 651 m m t t t e 0\end{array}$

Where LLLL is a location specification, $\mathrm{mm}$ is the material designation, ttt is the time after shutdown specification, and e is the energy group number. See Appendix $A$ for description of the available files. $F_{m}$ and $G_{m}$ are expressed in floating point form.

Under normal circumstances, material energy files need not be made up; only the Type 01 and Type 02 cards plus material and time after shutdown specifications are necessary. New material energy files should be set up with the as sistance of computer group personnel.

\section{II-3 Output}

Output of the 650 consists of five cards, one for each energy group.

$$
\begin{array}{rll}
\text { Col } & 1-10 & 0615500003 \\
11-20 & 654 \text { PPPP000 } \\
21-30 & \mu_{s} \\
31-40 & \mathrm{~S}_{\mathrm{c}} \\
41-78,80 & \text { Zeros } \\
79 & \mathrm{e}
\end{array}
$$

These cards are ready to be sorted with the material energy files of Program 654. 


\section{II -4 Timing}

The time required to run Program 651 is approximately 1 and $1 / 2$ minutes including read-in.

III. PROGRAM NO. 652

\section{II -1 Description}

Program 652 callculates the average gamma source values for materials in the reactor shield for the five energy groups. These data are punched out on cards for use in Program 653 a In addition, material and geometry information is set up in machine storage for Programs 653 or 654 .

In order to obtain source values throughout the shield, the shield is divided into regions of constant composition. There may be up to 25 regions of the shield with a total maximum of four different materials. Each region is further divided into a number of material slabs. There are then obtained five average gamma source values for each of these slabs based on the shield material and fast and thermal fluxes at the slab surfaces or boundaries.

The equations used in these calculations are -

$$
\begin{aligned}
& \left(S_{r}\right)_{n}=\left[F_{m} \bar{\phi}_{m}+G_{m} \bar{\phi}\right]_{n} \\
& \left(\bar{\phi}_{n}=\frac{\left(\phi_{n, n}\right)_{n}-\left(\phi_{m}\right)_{n-1}}{2} \quad\left(\bar{\phi}_{f}\right)_{n}=\frac{\left(\phi_{t}\right)_{n}-\left(\phi_{f}\right)_{n-1}}{2}\right.
\end{aligned}
$$

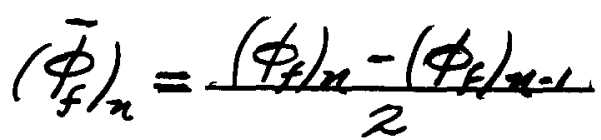

where $\mathrm{m}=$ material index (shield)

$\mathrm{n}$ = space point index

$\left(\phi_{f}\right)_{n}\left(\phi_{N_{n}}\right)_{n}=$ fast and thermal fluxes at the various space points in the shield - neutrons $/ \mathrm{cm}^{2}$ sec

$F_{m}, G_{m}=$ shield gamma parameters for fast and thermal neutrons see (1)

Inasmuch as the shielding codes were written with the two-group Prod code (3) calculations in mind, much of the shielding terminology is a reflection of that found in (3). Users of the shielding codes should become familiar with the Prod code notation. 


\section{III-2 Input}

Depending on whether Program 652 is to be used for Program 653 or 654, there will be either five or three different types of cards required for Program 652. In the following outline, the first three kinds of cards are required for both Programs 653 and 654; the last two kinds are required for Program 653 only in order to get the source value cards. Program 652 is used only to set up the material and geometry information in storage when used in conjunction with Program 654.

1. Type 01 Master Card 1 required

Col $\begin{aligned} 1-10 & \text { PPPP000001 } \\ 11-40 & \text { blank } \\ 41-50 & \text { 0000KK0000 } \\ 51-80 & \text { blank }\end{aligned}$

where $\mathrm{KK}=$ number of regions in the shield plus the number of regions in the core PPPP $=$ case number

2. Type 01 Shield Card 1 required This card is used both for Program 652 and Program 653

Col $\begin{aligned} 1-10 & \text { PPPP00ffo1 } \\ 11-20 & \text { abcdefthij } \\ 21-30 & \text { klmnopqrst } \\ 31-40 & \text { uvwxyz0000 } \\ 41-50 & \text { äbcdefghij } \\ 51-60 & \text { kimnopqrat } \\ 61-70 & \text { uvwxyz0000 } \\ 71-80 & \text { Zeros }\end{aligned}$

where PPPP = case number

ff = number of regions in the shield

$a, b, c, \ldots, y=$ material specification on shield regions $1,2,3, \ldots 25$. See $Q$ in Appendix B for proper specification. Maximum of 4 shield materials

$\overline{\mathrm{a}}, \overline{\mathrm{b}}, \overline{\mathrm{c}}, \ldots, \overline{\mathrm{y}}=$ dose specification on shield regions $1,2,3, \ldots 25$

$=8$ if dose is required in the region

$=9$ if dose is not required in the region

Note that there is a maximum of 25 shield regions; there may, of course, be less. There should be only ff values of material specification and dose specification. Remaining spaces should be zero. 
These cards are of the same format as the Prod Type 04 cards. This format is outlined here for convenience of the user.

Col $\begin{aligned} 1-10 & \text { PPPP000C04 } \\ 11-20 & \mathrm{~N}_{1} \times 10^{-6} \\ 21-29 & \Delta r_{1} \times 10^{-1} \\ 30 & \delta_{1} \\ 31 \propto 40 & \mathrm{~N}_{2} \times 10^{-6} \\ 41-49 & \Delta r_{2} \times 10^{-1} \\ 50 & \delta_{2} \\ 51-60 & \mathrm{~N}_{3} \times 10^{-6} \\ 61-69 & \Delta r_{3} \times 10^{-1} \\ 70 & \delta_{3} \\ 71-80 & \text { Zeros }\end{aligned}$

where PPPP = case number

$C=$ card number, $i_{0} e_{\circ}, 1,2$, etc

$\mathrm{N}_{\mathrm{i}}=$ space point index for the outermost boundary of region $i$. This includes core regions.

$\Delta r_{i}=$ mesh point spacing in region $\mathrm{i}-\mathrm{cm}$

$\delta_{t}=0$ if region $i$ is not a core region

$\delta_{i}=1$ if region $i$ is a core region

Within the framework of the shielding codes, all core regions (fuel regions) must be in contact with each other. Thus on successive Type 04 cards, once becomes zero, succeeding $\delta$ 's must also be zero. In addition, the first region $(i=1)$ must be a fuel region. Care must be taken that the total number of regions as specified on the Type 01 master card (KK) less the total number of $\delta=1$ values from the Type 04 cards be equal to the number of shield regions (ff) as specified on the Type 01 shield card.

All values on Type 04 cards are expressed in fixed point form.

The following information is required for Program 652 use with Program 653 but not for use with Program 654.

4. Shield Flux Cards $\frac{2(\mathrm{NN}+6)}{7}$ required

These cards are similar in format to the Prod flux cards except that the flux values on the shield flux cards are (a) real fluxes (neutrons $/ \mathrm{cm}^{2} \mathrm{sec}$ ) and (b) expressed in floating point form. 


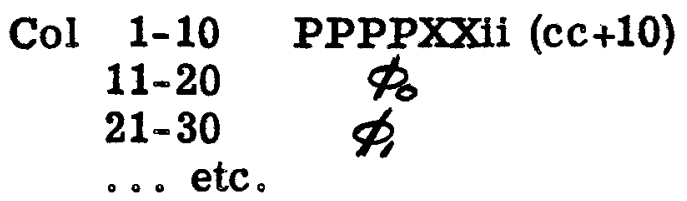

where PPPP = case number

$X X=$ anything

ii = 01 for fast flux, 02 for thermal flux

$c c=$ card number, $i_{\text {. }} e_{.}, 01,02$, etc, for each energy

$\mathrm{NN}=$ number of mesh points in core and shield

There must be enough flux cards for each energy group to give the flux at each mesh point in both core and shield with the flux values corresponding to the $\mathrm{N}_{\mathrm{i}}$ points on the Type 04 cards.

5. Material Energy File Cards

$4 \mathrm{req} / \mathrm{energy}$

$\begin{array}{rll}\text { Col } & 1-10 & \text { 04LLLL0004 } \\ 11-20 & F_{m} \\ 21-30 & \mathrm{G}_{\mathrm{m}} \\ 31-50 & \text { Zeros } \\ 51-60 & \text { blank } \\ 61-70 & \text { Material Name } \\ 71-80 & 652 m m t t t e 0\end{array}$

where LLLL is a location specification, $\mathrm{mm}$ is the material number, ttt is the time after shutdown specification, and $e$ is the energy group number. See Appendix $B$ for description of the available files. Values of $F_{m}$ and $G_{m}$ are expressed in floating point form.

As with Program 651, material energy cards usually need not be made up for problems calculated; only the Type 01 master card, the Type 01 shield card, the Type 04 cards, plus the material and time after shutdown specifications and the flux cards if Program 653 is of interest, need be supplied. Again, new material energy files should be made up with the assistance of computer personnel.

\section{III-3 Output}

If Program 652 is used for preparation of stored information for Program 654, there is no card output. When used for Program 653, the output consists of gamma source cards, the number of which will depend upon the number of mesh points or source slabs in the shield. There are six source values punched per card and five sets of cards for the five gamma energy groups. 


$\begin{aligned} \text { Col } 1-10 & \text { QQ15RR000N } \\ 11-20 & S_{V_{i}} \\ 21-30 & S_{V_{i}} \\ \mathbf{3 1}-40 & S_{V_{i}} \\ 41-50 & S_{V_{i}} \\ 51-60 & S_{V_{i}} \\ 61-70 & S_{V_{i}} \\ 71-80 & \text { PPPP00cce0 }\end{aligned}$

where $Q Q=$ number of source cards per energy group

$\mathrm{RR}=6 \mathrm{CC}-5=$ location specification

$\mathrm{N}=$ number of source values on card

$\mathbf{S}=$ source values - gamma $/ \mathrm{cm}^{3} \mathrm{sec}$

PPPP = case number

$\mathrm{e}=$ energy group number

$c c=$ card number $, i_{\circ} e_{\circ}, 01,02,03, \ldots$

$i=$ source slab index,$i$. e., $1,2,3, \ldots$

These cards as punched are ready for use as partial input to Program 653.

The stored information developed for Programs 653 and 654 is of the following form:

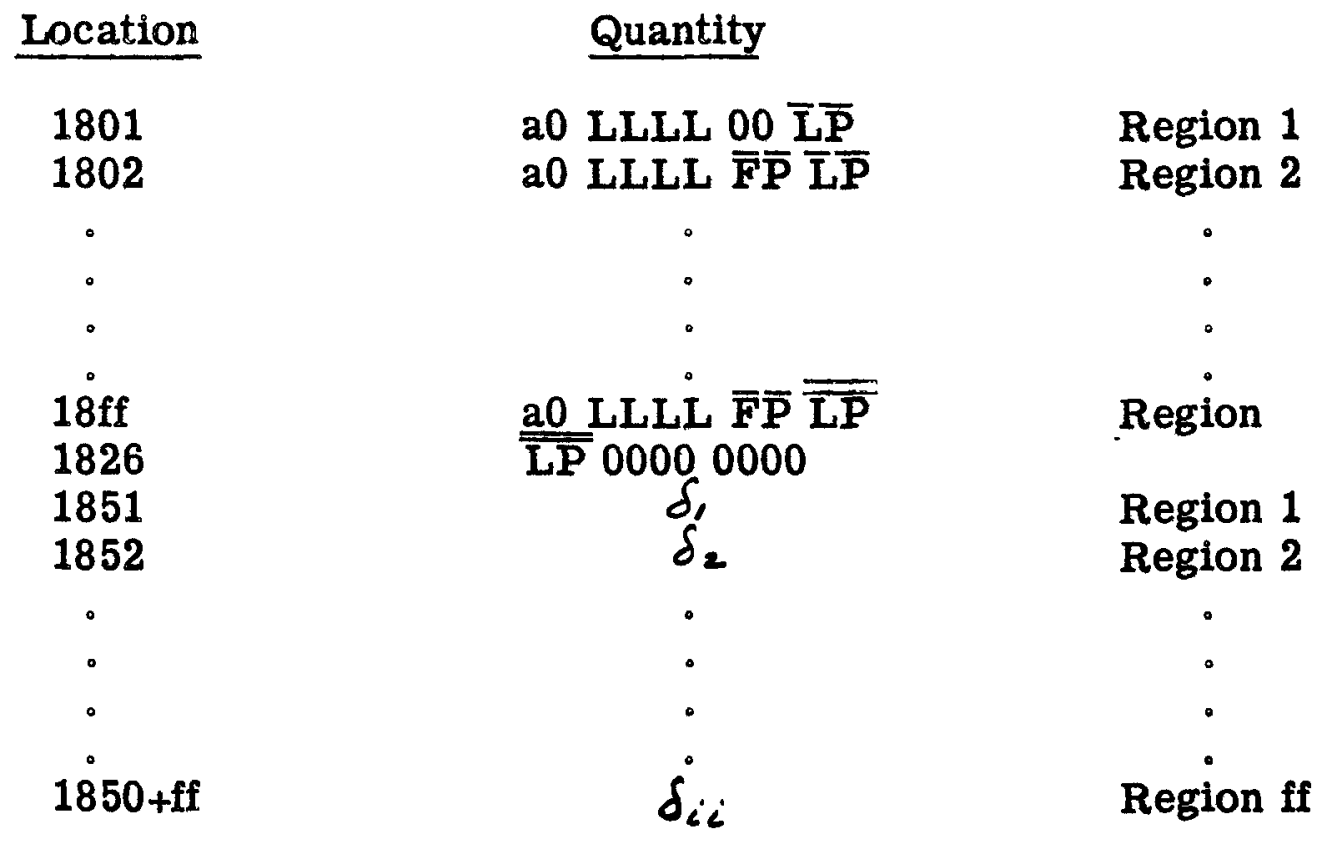

where $\quad a=8$ if dose is specified; otherwise 9

LLLL = material energy location spec. See Appendix C

$\overline{\mathrm{FP}}=$ mesh point index for first point in region 1

$\overline{L P}=$ mesh point index for last point in region 1

LP $=$ mesh point index for last point in shield

$\mathrm{ff}=$ number of regions in shield; $\max$ of 25

$\delta_{i}=$ mesh point spacing in floating point form for region $\mathrm{i}-\mathrm{cm}$ 


\section{III -4 Timing}

When used for Program 654, Program 652 requires about $11 / 2$ minutes including program and data loading.

When used for Program 653, Program 652 time depends upon the number of regions and mesh points in the problem. Roughly, Program 652 requires about $3 \sim 6$ minutes when used to obtain the source cards.

\section{PROGRAM NO. 653}

\section{IV -1 Description}

Program 653 calculates the gamma dose rate due to activation gammas from the reactor shield at specified points in specified regions of a cylindrical reactor shield. There may be up to 25 regions of constant composition in the shield comprised of up to a total of four different shield materials. Five energy groups of gamma photons are considered giving rise to five dose values at each dose point.

The background for these calculations is outlined in (2), (4), and (5). The machine is programmed to solve the following equations for each group and each dose point.

$$
\begin{gathered}
D_{1}=\sum_{s s} \sqrt{\frac{r_{s}}{r_{d}}} \frac{S_{x}}{2 \mu_{s}}\left[E_{2}\left(b_{T}\right)-E_{2}\left(b_{T}+\mu_{s} \delta_{s}\right)\right] \\
D_{2}=\sum_{s s} \frac{r_{s}}{r_{d}} \frac{S_{n} B_{0}}{2 \mu_{s}}\left[E_{2}\left(b_{T}\right)-E_{2}\left(b_{T}+\mu_{s} \delta_{s}\right]\right. \\
D_{1}^{*}=\frac{D_{1}}{C_{e}} \quad D_{2}^{*}=\frac{D_{2}}{C_{e}} \\
b_{m}=\sum \mu_{m} \delta_{m} \quad \begin{array}{l}
\text { for each material between } \\
\text { the source slab and dose } \\
\text { point. Maximum of } 4 \text { values. }
\end{array}
\end{gathered}
$$




$$
\begin{gathered}
D_{1}=D_{2}=\frac{S_{n}}{2 \mu_{s}}\left[1-E_{2}\left(\mu_{s} \delta_{s}\right)\right] \quad \begin{array}{l}
\text { where source slab is } \\
\text { adjacent to dose point }
\end{array} \\
B(b)=\prod^{m}\left[A, e^{\left.-\alpha_{1} b_{m}+\left(1-A_{1}\right) e^{-\alpha_{2} b_{m}}\right]}\right. \\
b_{5}=\sum_{n=1}^{\sum_{n}^{*}} \mu_{m} \delta_{m} \quad \begin{array}{l}
\text { for all materials between } \\
\text { source slab and dose point }
\end{array}
\end{gathered}
$$

where $\quad r_{s}=$ distance from the center of core to the interface of source slab nearest the dose point $-\mathrm{cm}$

$r_{d}=$ distance from the center of core to the dose point $-\mathrm{cm}$

$S_{n}=$ average gamma source value for source slab - photons $/ \mathrm{cm}^{3} \mathrm{sec}$

$\mu_{s}=$ absorption coefficient of source slab $-\mathrm{cm}^{-1}$

$\delta_{i}=$ thickness of imaginary slab in shield $-\mathrm{cm}$

$\mathrm{E}_{2}=$ exponential integral function

$B(b)=$ buildup factor

$\mathrm{C}_{\mathrm{e}}=$ proportionality factor to convert from photons $/ \mathrm{cm}^{3} \mathrm{sec}$ to $\mathrm{r} / \mathrm{hr}$

$A_{1}=$ buildup parameters

$\mathrm{D}_{1}=$ dose with buildup factor of $1-$ photons $/ \mathrm{cm}^{3} \mathrm{sec}$

$D_{1}^{*}=$ dose with buildup factor of $1-\mathrm{r} / \mathrm{hr}$

$\mathrm{D}_{2}=$ dose with calculated buildup factor - photons $/ \mathrm{cm}^{3} \mathrm{sec}$

$D_{2}{ }^{*}=$ dose with calculated buildup factor $-\mathrm{r} / \mathrm{hr}$

In the calculation, the dose point is selected on the basis of stored information set up by Program 652. The dose at this point is then calculated by summing the dose contribution from each and every source slab in the reactor shield both with unity buildup factors and calculated buildup factors. Gamma source values for each energy and each source slab are obtained from Program 652 output. Upon the obtaining of the dose value for the energy involved, a card is punched. with the dose information for that point.

IV-2 Input

1.653 Master Card

1 required

$\begin{array}{rl}\text { Col } 1-10 & \text { PPPP00ff01 } \\ 11-20 & T \\ 21-30 & R_{0} \\ 31-80 & \text { blank }\end{array}$

where PPPP = case number

ff $=$ total number of shield regions

$T=$ distance from core surface to last point in the shield $-\mathrm{cm}$

$R_{0}=$ core radius $=\mathrm{cm}$ 
The values of $T$ and $R_{0}$ must be entered in floating point form.

2. Source Cards

These cards result from Program 652. See Section III-3 for card format.

3. Material Energy Files - Type A

$4 \mathrm{req}^{\prime} \mathrm{d} / \mathrm{energy}$

Col $\begin{array}{rl}1-10 & 05 \text { LLLL } 0005 \\ 11-20 & \mu \\ 21-30 & \text { zeros } \\ 31-40 & A_{1} \\ 41-50 & \alpha_{1} \\ 51-60 & \alpha_{2} \\ 61-70 & \text { Material Name } \\ 71-80 & 653 \mathrm{~mm} 000 \mathrm{e} 0\end{array}$

where LLLL is a location specification, $\mu$ is the absorption coefficient which must not be zero. $A_{1}, \alpha_{1}$, and $\alpha_{2}$ are buildup parameters, $\mathrm{mm}$ is the material specification, and $\mathrm{e}$ is the energy group number. See Appendix $\mathrm{C}$ for available files. Values of $A_{1}, \mu, \alpha_{1}$ and $\alpha_{2}$ are expressed in floating point form.

4. Material Energy Files - Type B

$1 \mathrm{req} \cdot \mathrm{d} / \mathrm{energy}$

$\begin{array}{rll}\text { Col } 1-10 & 0515000001 \\ 11-20 & \mathrm{C}_{\mathrm{e}} \\ 21-60 & \text { blank } \\ 61-70 & \text { PROP. CONS. } \\ 71-80 & 65300000 \mathrm{e} 0\end{array}$

where $C_{e}$ is the conversion constant to change from photons $/ \mathrm{cm}^{3} \mathrm{sec}$ to $\mathrm{r} / \mathrm{hr}$ and $e$ is the energy group number. $C_{e}$ is in floating point form.

Under normal usage the source cards result from Program 652 and Material Energy File cards are obtained from files as listed in Appendix C. Thus, the user usually need supply only the master card and four material specifications for Program 653.

\section{IV -3 Output}

Each output card contains dose information for one dose point at one energy. The number of cards resulting for each energy will depend upon the number of regions specified for dose results in Program 652 and the number of space points in these regions. Each card contains the following information. 


$\begin{array}{rll}\text { Col } 1-10 & 653 P P P P e c c \\ 11-30 & \text { zeros } \\ 31-40 & \mathrm{D}_{1} \\ 41-50 & \mathrm{D}_{1}^{*} \\ 51-60 & \mathrm{D}_{2} \\ 61-70 & \mathrm{D}_{2}^{*} \\ 71-80 & \mathrm{xx00000000}\end{array}$

where PPPP is the case number, $e$ is the energy group number, cc is the card number starting with 01 for each energy, $\mathrm{xx}$ is the dose point index, and the other quantities punched out in floating point form are defined in Section IV -1 .

\section{IV -4 Timing}

The time required by Program 653 for each dose point depends primarily on the number of mesh points (source slabs) in the shield. For each dose point and each energy

$$
\mathrm{T} \equiv .35 \mathrm{~N} \text { (minutes) }
$$

where $\mathrm{N}$ is the number of source slabs in the shield. For all five energies, the equation becomes

$$
\mathrm{T} \cong 1.8 \mathrm{~N} \text { (minutes) }
$$

for each dose point.

V. PROGRAM NO. 654

\section{V-1 Description}

Program 654 calculates the gamma dose rate due to gamma photons from the reactor core at specified points in specified regions of a cylindrical reactor shield. There may be up to 25 regions of constant composition in the shield comprised of up to a total of four different shield materials. Five energy groups of gamma photons are considered giving rise to five dose values at each dose point.

The background for these calculations is outlined in (2), (4), and (5). Following the methods outlined essentially in these references, the machine is programmed to solve the following equations for each energy group and each dose point. 


$$
\begin{aligned}
& m \cong A_{0}+A_{1}\left(\frac{a}{R_{0}}\right)+A_{2}\left(\frac{a}{R_{0}}\right)^{2}+A_{3}\left(\frac{a}{R_{0}}\right)^{3}+A_{4}\left(\frac{a}{R_{0}}\right)^{4} \\
& \left.z \cong \frac{m}{\mu_{5}} B_{0}+B_{1} b^{*}+B_{2} b^{* 2}+B_{3} b^{* 3}+B_{4} b^{* 4}\right\} \frac{a}{R_{0}} \leq 0 \\
& z \cong \frac{1}{\mu_{5}}\left\{C_{1}\left(\mu_{5} R_{0}\right)+C_{2}\left(\mu_{5} R_{0}\right)^{2}+C_{3}\left(\mu_{5} R_{0}\right)^{3}+C_{4}\left(\mu_{5} R_{0}\right)^{4}\right\} \frac{a}{R_{0}}>9
\end{aligned}
$$

where $b^{*}=\sum_{x=1}^{n^{*}} \mu_{m} \delta_{n} \begin{aligned} & \text { for all materials between core surface and dose point } \\ & \text { and } A_{i}, B_{i} \text { and } C_{i} \text { are constants resulting from the }\end{aligned}$ $\Gamma \rho$ curve fitting described in (2).

$b_{m}=\sum \mu_{m} \delta_{m}$ for each material between core surface and dose point. Maximum of 4 values.

$$
\begin{aligned}
& \bar{b}=\sum_{n=1}^{n *} \mu_{m} \delta_{n}+\mu_{s} Z
\end{aligned}
$$

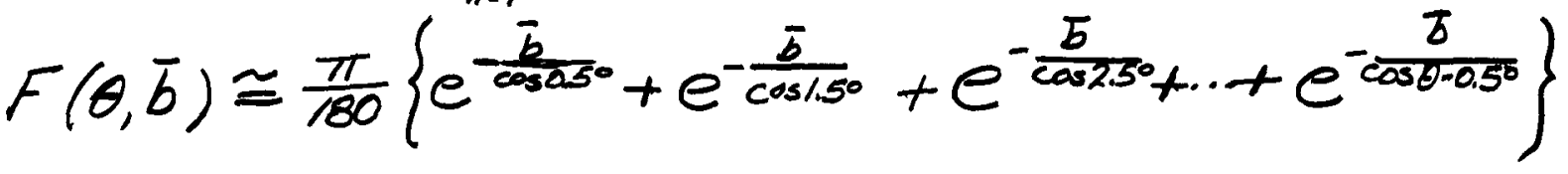

$$
\begin{aligned}
& B(b)=\mathbb{I}\left\{A_{1 m} e^{-\alpha_{1 m} b_{m}}+\left(1-A_{1 m}\right) e^{-\alpha_{2 m} b_{m}}\right\} \\
& D_{1}=\frac{S_{c} R_{0}^{2}}{2(a+z)} F(b, \theta) \\
& D_{2}=\frac{D_{1}}{C_{e}} \\
& D_{1}^{*}=D, B(b) \\
& D^{2 *}=\frac{D_{2}}{C_{e}}
\end{aligned}
$$

where $\quad z=$ self absorption distance $-\mathrm{cm}$

$a=$ distance from core surface to dose point $-\mathrm{cm}$

$\mathrm{R}_{\mathrm{o}}=$ core radius $-\mathrm{cm}$

$\mu_{s}=$ core absorption coefficient $-\mathrm{cm}^{-1}$

$\delta_{n}=$ mesh point spacings in shield regions $-\mathrm{cm}$

$\mu_{m}=$ absorption coefficients for shield materials $-\mathrm{cm}^{-1}$

$\mathrm{h}=$ core height $-\mathrm{cm}$

$\mathrm{n}^{*}=$ mesh point index at dose point

$S_{c}=$ core gamma source value - photons $/ \mathrm{cm}^{3} \mathrm{sec}$

$B(b)=$ buildup factor

$\alpha, \alpha_{2}, A_{y_{1}}=$ buildup parameters

$\mathrm{D}_{1}=$ dose with bulldup factor of 1 - photons $/ \mathrm{cm}^{2} \mathrm{sec}$

$D_{2}=$ dose with buildup factor of $1-r / h r$ 


\section{V-2 Input}

There are four types of cards necessary for Program 654 in addition to the stored information set up by Program 652. The card formats are as follows:

1. $R_{0}$ h Card

1 required

$$
\begin{array}{rrl}
\text { Col } & 1-10 & \text { PPPP00ff01 } \\
11-20 & R_{0} \\
21-30 & \text { h } \\
31-80 & \text { blank }
\end{array}
$$

where PPPP = case number

$$
\begin{aligned}
\mathbf{f f} & =\text { total number of shield regions } \\
\mathbf{R}_{\mathrm{O}} & =\text { core radius }-\mathrm{cm} \\
\mathbf{h} & =\text { core height }-\mathrm{cm}
\end{aligned}
$$

The values of $R_{0}$ and $h$ must be entered in floating point form (see Appendix D)。

2. Source Cards $1 \mathrm{req}$ 'd/energy

These cards are the output of Program 651. See Section II-3 for card format.

3. Material Energy File Cards - Type A

$4 \mathrm{req}^{\prime} \mathrm{d} /$ energy

$$
\text { Col } \begin{array}{rl}
1-10 & 06 \text { LLLL } 0005 \\
11-20 & \mu \\
21-30 & \text { zeros } \\
31-40 & A_{1} \\
41-50 & \alpha_{1} \\
51-60 & \alpha_{2} \\
61-70 & \text { Material Name } \\
71-80 & 654 \mathrm{~mm} 000 \mathrm{e} 0
\end{array}
$$

where LLLL is a location specification, $\mu$ is the absorption coefficient, $\mathrm{A}_{1}, \alpha_{1}$, and $\alpha_{2}$ are buildup parameters, $\mathrm{mm}$ is the material designation, and $e$ is the energy group number. $A_{1}, \alpha_{4}, \alpha_{2}$, and $\mu$ are in floating point form. See Appendix $B$ for avallable flles.

4. Material Energy File Cards - Type B

$1 \mathrm{req} / \mathrm{d} / \mathrm{energy}$

$$
\begin{array}{rll}
\text { Col } & 1-10 & 0615000001 \\
11-20 & \mathrm{C}_{\mathrm{e}} \\
21-60 & \text { blank } \\
61-70 & \text { PROP. CONS } \\
71-80 & 65400000 \mathrm{e} 0
\end{array}
$$


where $C_{e}$ is the conversion constant to change from photons $/ \mathrm{cm}^{2} \mathrm{sec}$ to $\mathrm{r} / \mathrm{hr}$ and $e$ is the energy group number $C_{e}$ is in floating point form.

Under normal usage, the source cards result from Program 651 and Material Energy File Cards are obtained from files as listed in Appendix C. Thus, in addition to the $R_{0} h$ card the user must give four material specifications.

\section{V-3 Output}

Each output card contains dose information for one dose point at one energy. The number of cards resulting for each energy will depend upon the number of regions specified for dose results in Program 652 and the number of mesh points in these regions. Each card contains the following information:

Col $\begin{array}{rl}1-10 & 654 \text { PPPPecc } \\ 11-20 & \mu_{s} Z \\ 21-30 & \mathrm{~B}^{(\mathrm{b})} \\ 31-40 & \mathrm{D}_{1} \\ 41-50 & \mathrm{D}_{2} \\ 51-60 & \mathrm{D}_{1}^{*} \\ 61-70 & \mathrm{D}_{2}^{*} \\ 71-80 & \mathrm{xx} 00000000\end{array}$

where PPPP is the case number, $e$ is the energy group number, cc is the card number starting with 01 for each energy, $x x$ is the dose point index, and other quantities punched out in floating point form are defined in Section IV-1.

In the calculation of $z$ for a dose point, unless $a / R_{0}>9$ the quantity $\mu_{0}$ $\left(a+R_{0}\right)$ is computed. If this value is greater than 20 , the code cannot calculate $z$. In this event, columns 11-70 are replaced with 8's, the card is punched and calculation proceeds to the next energy. Since dose points are calculated outward from the core, once $\left(a+R_{0}\right)>20$, all subsequent values of this quantity for the same energy will also be greater than 20 , and there is no point in attempting to calculate dose values further out in the shield.

\section{V-4 Timing}

Program 654 requires from 1 to 2 minutes per dose point per energy. Thus in general, barring values of $\mu_{s}\left(a+P_{b}\right)>20$, the over-all time required will be roughly

$$
\mathrm{T} \cong 8 \mathrm{~N} \text { (Minutes) }
$$

where $\mathrm{N}$ is the number of dose points to be calculated. 


\begin{tabular}{l} 
VI. MACHINE OPERATION \\
OF PROGRAMS $651,652,653,654$ \\
\hline
\end{tabular}

VI 1 General

The console settings on all programs are

$\begin{array}{ll}\text { Storage Entry Switches } & 701951 \times X X X+ \\ \text { Programmed Switch } & \text { Stop } \\ \text { Half Cycle Switch } & \text { Run } \\ \text { Address Selection Switches } & \text { Anything } \\ \text { Control Switch } & \text { Run } \\ \text { Display Switch } & \text { Any but Read-out or Read-in } \\ \text { Overflow Switch } & \text { Stop } \\ \text { Error Switch } & \text { Stop }\end{array}$

VI-2 Input Deck Make-up

1. Program 651

a) Program 651 deck

b) Type 01 eerd

c) Type 02 card

d) Material Energy File Cards*

* Select for proper time specification by sorting on Col. $78,77,76$. Select specified material files by sorting on Col. 75, 74. Sort cards thus obtained on Col. 79 for proper sequencing. There should be seven cards for each energy group number.

2. a) Program 652 deck

b) Type 01 Master card

c) Type 01 shield card

d) Type 04 cards, sorted on Col. 8

e) Flux cards, sorted on Col.10,9,8

f) Material Energy File Cards*

* Select for proper time specification by sorting on Col. 78, 77, 76 . Select specified material files by sorting on Col. 75, 74. Sort cards thus obtained on Col. 79 for proper sequencing. There should be four cards for each energy group number. 


\section{Program 653}
a) Program 653 deck
b) 653 Master card
c) Source cards and material energy file cards*

*1. Select specified materials files by sorting Type A Material Energy File cards on Col. 75, 74. Sort with Type B Material Energy File cards on Col. 79 for proper sequencing. There should be five cards for each energy group.

2. Sort source cards on Col。 $78,77,76$.

3. Place deck from step 2 behind deck resulting from step 1 and sort on Col. 79 .

Note that Program 652 operation must immediately precede Program 653 operation in order that information developed by Program 652 is stored in the 650 memory.

Due to the length of calculation of Program 653, it may be necessary to stop calculation and restart at a later time. This is easily done at the end of the calculation for an energy group as follows:

1. Stop calculations by setting "1988" in address selection switches, control switch to "address stop" and letting calculation proceed until machine stops with 2209181988 in program register.

2. Restart calculation by

a) Re-running Program 652 to 0100000579 stop.

b) Load Program 653 deck plus 653 master card.

c) Machine will stop with 2419921988 in program register after end of file is pressed.

d) Load e000000000: into 1787 where $e$ is the next energy to be calculated.

e) Place material energy file cards and source card starting with this energy in the read feed.

f) No-op to 1988

4. Program 654

a) Program 654 deck

b) $R_{0} h$ card

c) Source cards and material energy file cards*

* Select specified material files by sorting Type A Material Energy file cards on Col. 75, 74. Sort cards thus obtained with Type B material energy flle cards and source cards on Col. 79 for proper sequencing. There should be six cards for each energy group number. 
Note that Program 652 operation must immediately precede Program 654 operation in order that information developed by Program 652 is stored in the 650 memory.

VI 3 Machine Stops

1. Program 652

Program Register

0000003333

0000004444

2. Program 652

0111111111

0122222222

0133333333

0144444444

0155555555

0166666666

0100000579

0199999999

3. Program 653

0000002222

0000003333

0000005555

0000006666

4. Program 654

0000003333 0000004444 0000005555
Improper Type 01 master card Improper Type 01 shield card Improper Type 04 card Incorrect region count on Type 01 Master card Improper Flux card Improper Material Energy File Card Program 654 preparation is complete or Program 653 preparation is complete if source cards have been obtained previously. Press computer start button to continue calculation and obtain source cards for Program 653.

Calculation for Program 653 is complete.
Improper Master Card Improper source or Energy card Problem calculation is complete Improper material selection
Improper $R_{0} \mathbf{h}$ card

Improper material energy file card

Problem calculation is complete

In cases of improper cards, remove deck from read hopper, correct card sequence or error and start program loading from the start except where stop 
occurs on Program 653 or Program 654 Material Energy File and source card assemblies. In this case, correct the card assembly, set storage entry switches to 0000001974 and load remainder of deck preceded by the complete corrected assembly, i.e., all cards with same energy group number.

Machine stops occurring in Programs 653 and 654 in no way affect the information stored by Program 652。 
(1) APAE Memo 145 "Gamma Production in the Core and Primary Shield of Thermal Reactors", $J_{\circ} T_{\circ}$ Lence and $P_{\circ}^{\prime}$ P.F。 Bujalski, May 1958

(2) AP-Memo-52 To be reissued.

(3) KAPL 1415 (Part 1 - Equations, G。J。Habetter, Dec。1955) and KAPL1531 (Part 2 - Machine Program, V.A. Walbran, April 1956) "One-SpaceDimensional Multigroup for the IBM 650".

(4) 'Reactor Shielding Design Manual"', McGraw Hill, 1956

(5) APAE -35 "APPR-1 Research and Development Program, "Shielding Experiments and Analysis - Task No。VI", S.S.Rosen, October 1958 
MATERIAL ENERGY FILE SPECIFICATIOHS FOR PROGRAM 651

1. Available Files

\begin{tabular}{cccl} 
Group & mm & LLLL & \multicolumn{1}{c}{ Material } \\
\hline A & 00 & 1300 & Unassigned \\
B & 01 & 1200 & Graphite \\
C & 02 & 1100 & 304SS with Cobalt \\
D & 03 & 1100 & 304SS without Cobalt \\
E & 04 & 1150 & $\mathrm{H}_{2} \mathrm{O}$ \\
F & 05 & 1000 & $\mathrm{U}^{25}$ \\
G & 06 & 1000 & $\mathrm{U}^{25} \mathbf{0}_{2}$ \\
& 07 & 1250 & $\mathrm{Th}_{232}$ \\
& 08 & 1050 & $\mathrm{U}^{28}$ \\
& 09 & 1050 & $\mathrm{U}^{28} \mathbf{0}_{2}$
\end{tabular}

Only one file from each group may be used in one particular calculation and there must be one from each group, $i_{0} e_{.}$, there must be seven files specified even though some materials may not be present in the core; in this case the volume fractions of the unwanted materials are set equal to zero.

2. Time Specification

\begin{tabular}{|c|c|c|c|c|}
\hline ttt & \multicolumn{4}{|c|}{ Corresponds to } \\
\hline 000 & oper & tio & & \\
\hline 001 & 0.1 & ays & afte & shutdown \\
\hline 002 & 0.2 & $"$ & $"$ & $"$ \\
\hline 010 & 1.0 & $"$ & $"$ & $"$ \\
\hline 020 & 2.0 & " & $n$ & $n$ \\
\hline 040 & 4.0 & $"$ & $m$ & $"$ \\
\hline 060 & 6.0 & $m$ & $" 1$ & $"$ \\
\hline 080 & 8.0 & " & $"$ & $"$ \\
\hline 10 & 10.0 & $m$ & $"$ & $"$ \\
\hline
\end{tabular}

The user must specify the $t t t$ value along with other input. 
3. Energy Groups

Group No. e

1

2

3

4

5
Photon Energy Range

$>7 \mathrm{mev}$

5-7 mev

3-5 mep

1-3 mev

0-1 mev
Average Energy

$7 \mathrm{mev}$

$6 \mathrm{mev}$

$4 \mathrm{mev}$

$2 \mathrm{mev}$

$.75 \mathrm{mev}$

5,$1 ; \quad, 3$ 


\section{APPENDIX B \\ MATERIAL ENERGY FILE SPECIFICATIONS FOR PROGRAM 652}

1. Available Files

\begin{tabular}{|c|c|c|c|c|}
\hline Group & $\underline{\mathbf{Q}}$ & $\mathbf{m m}$ & LLLL & Material \\
\hline A & $\begin{array}{l}1 \\
1 \\
1 \\
1\end{array}$ & $\begin{array}{l}01 \\
06 \\
07 \\
09\end{array}$ & $\begin{array}{l}1100 \\
1100 \\
1100 \\
1100\end{array}$ & $\begin{array}{l}\text { Lead } \\
\text { 304SS, with Co } \\
\text { 304SS, No Co } \\
\text { Void }\end{array}$ \\
\hline B & 2 & 02 & 1200 & $\mathrm{H}_{2} \mathrm{O}$ \\
\hline C & $\begin{array}{l}3 \\
3 \\
3\end{array}$ & $\begin{array}{l}10 * \\
03 \\
08\end{array}$ & $\begin{array}{l}1300 \\
1300 \\
1300\end{array}$ & $\begin{array}{l}\text { Void* } \\
\text { Concrete } \\
\text { Boral }\end{array}$ \\
\hline D & $\begin{array}{l}4 \\
4\end{array}$ & $\begin{array}{l}04 \\
05\end{array}$ & $\begin{array}{l}1400 \\
1400\end{array}$ & $\begin{array}{l}\text { C-1015, with Co } \\
\text { C-1015, No Co }\end{array}$ \\
\hline
\end{tabular}

Only one file from each group may be used in a particular calculation and there must be one from each group, i.e., there must be four files specified even though there may be less than four materials in the shield.

The user must specify the $\mathrm{mm}$ value, the ttt value and on the Type 01 shield card, the $Q$ values. The ttt and energy values are the same as in Appendix $A$. 
1. Available Files

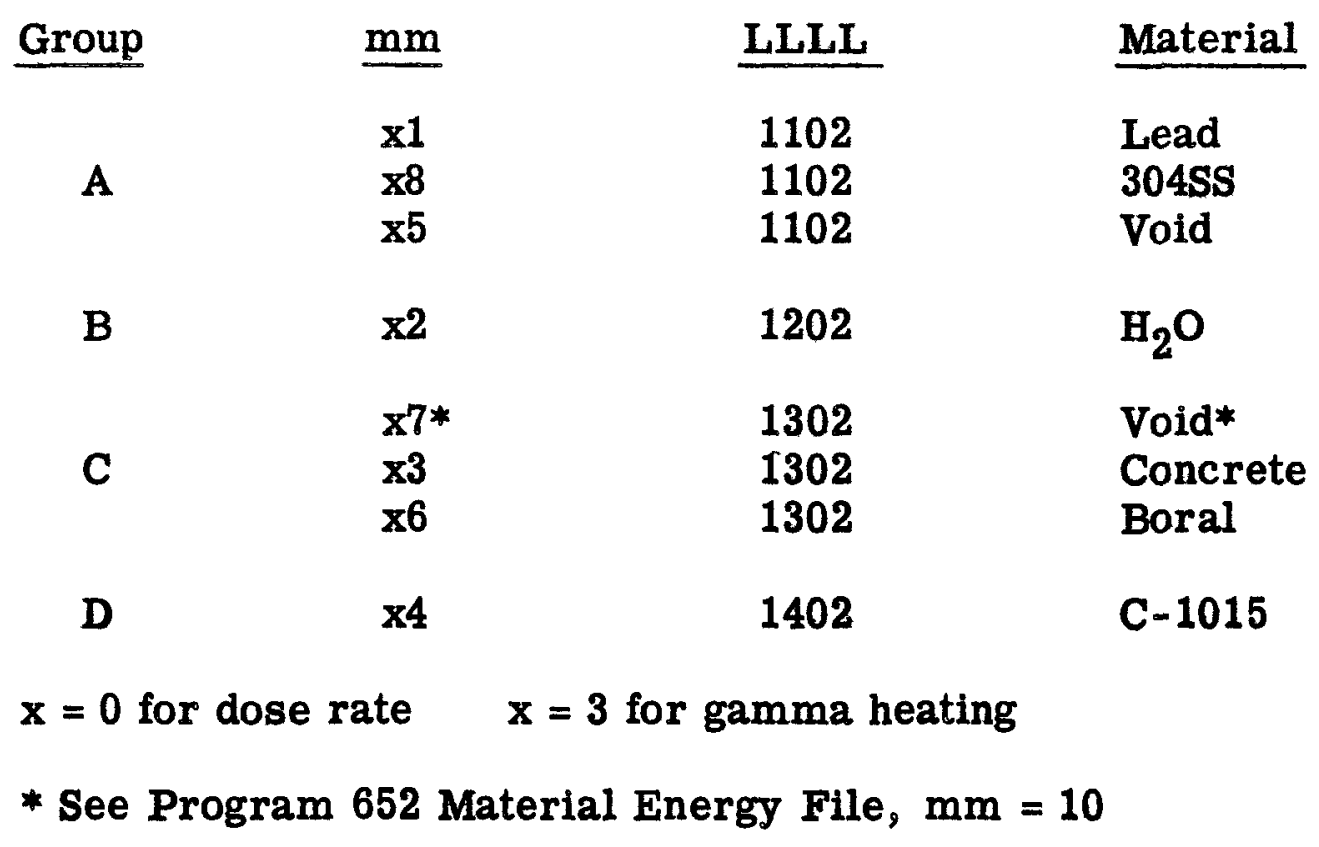

Only one file from each group may be used in one particular calculation and there must be one from each group, $i_{\text {. }} e_{\text {, }}$, there must be four files specified even though some materials may not be present in the shield.

Since the parameters in these files are time independent, they are suitable for either reactor operation or any time after shutdown. The user need specify only the four $\mathrm{mm}$ values with other input.

\section{Energy Groups}

Energy group structure is the same as for Program 651. 


\section{APPENDIX D}

\section{FLOATING POINT REPRESENTATION.}

Since the range of numbers encountered in shielding calculations is quite large, floating point arithmetic was used in all of the $65 \mathrm{x}$ programs.

To put a number into floating point form, it first is expressed as an eight digit number times a power of ten, i.e.,

$$
\pm \mathrm{x} . \operatorname{xxxxxxx} \cdot 10^{y}
$$

For example,

$$
\begin{aligned}
123.456 & =1.2345600 \times 10^{2} \\
.0006928 & =6.9280000 \times 10^{-4} \\
-1.23456 & =-1.2345600 \times 10^{0} \\
-.065432 & =6.5432000 \times 10^{-2}
\end{aligned}
$$

For the 650, a number is expressed as 10 digits plus an associated sign. Since a negative number may have a negative exponent, as in the last example, 50 is added to the actual exponent and the exponent itself is moved in front of the eight digit mantissa. The sign of the number is written either before or after the number. The above examples then become

5212345600

4669280000

$-5012345600$

$-4865432000$ 


\section{APPENDIX E}

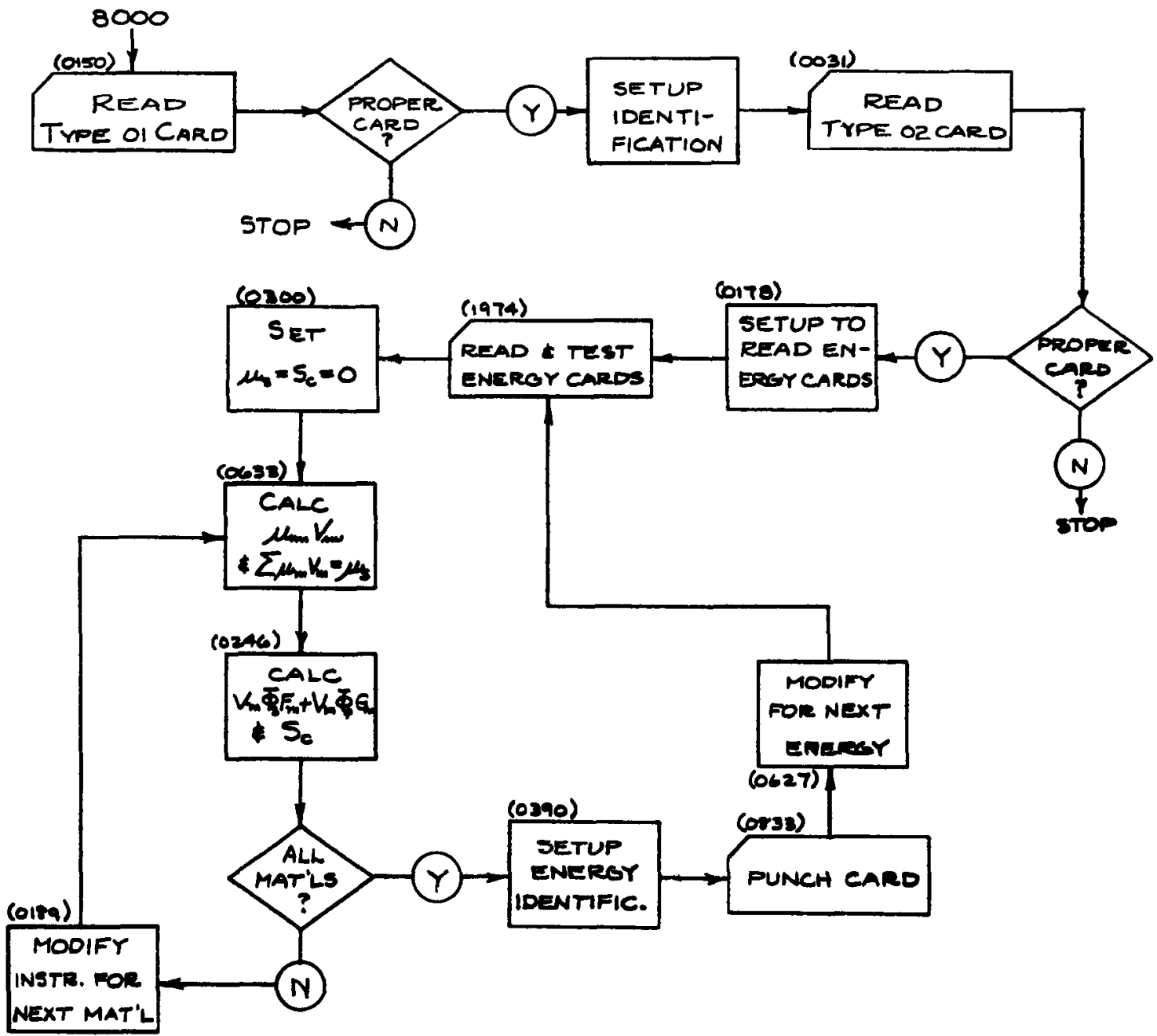

Flow Chart For Program 651 


\section{APPENDIX E}

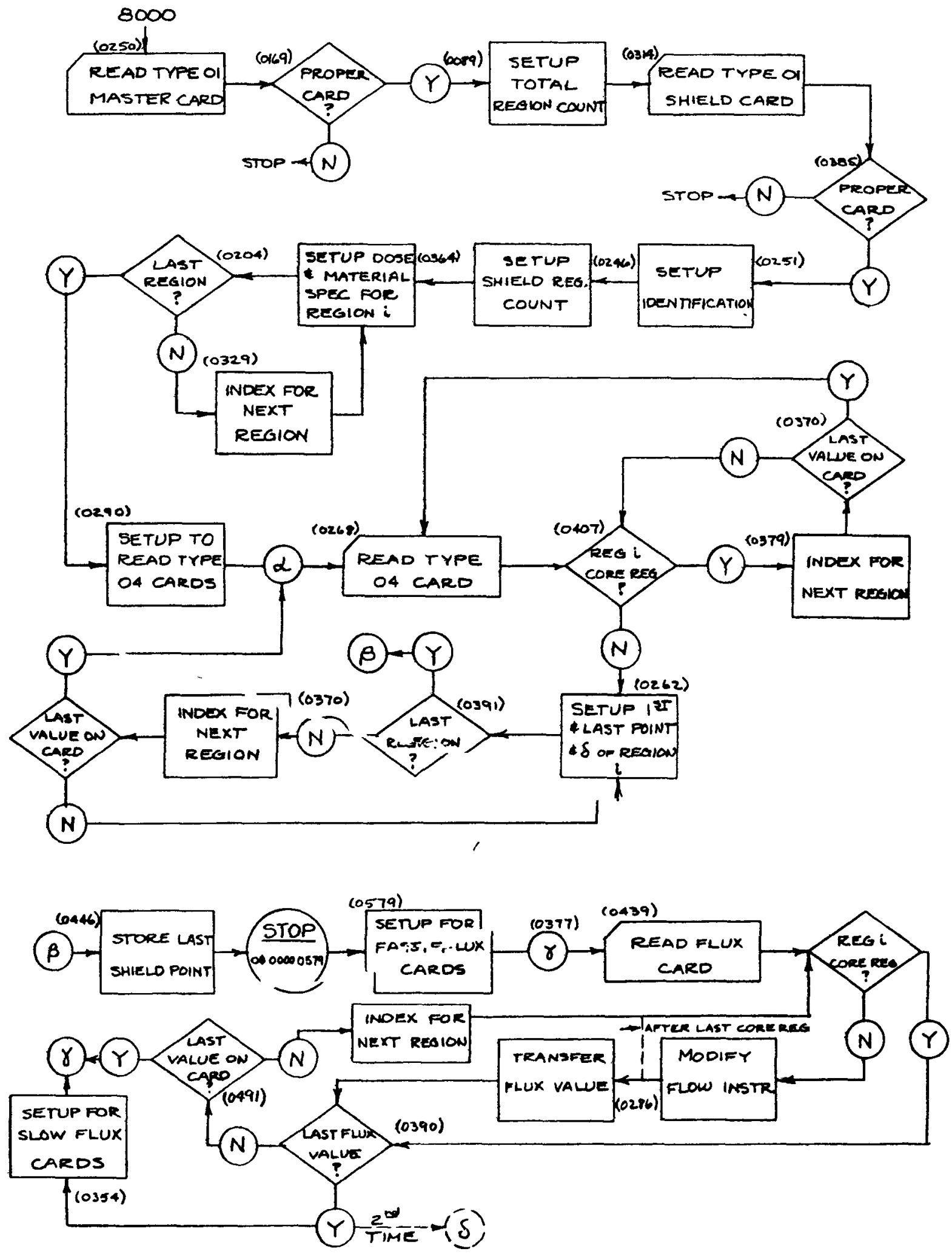

Flow Chart For Program 652 


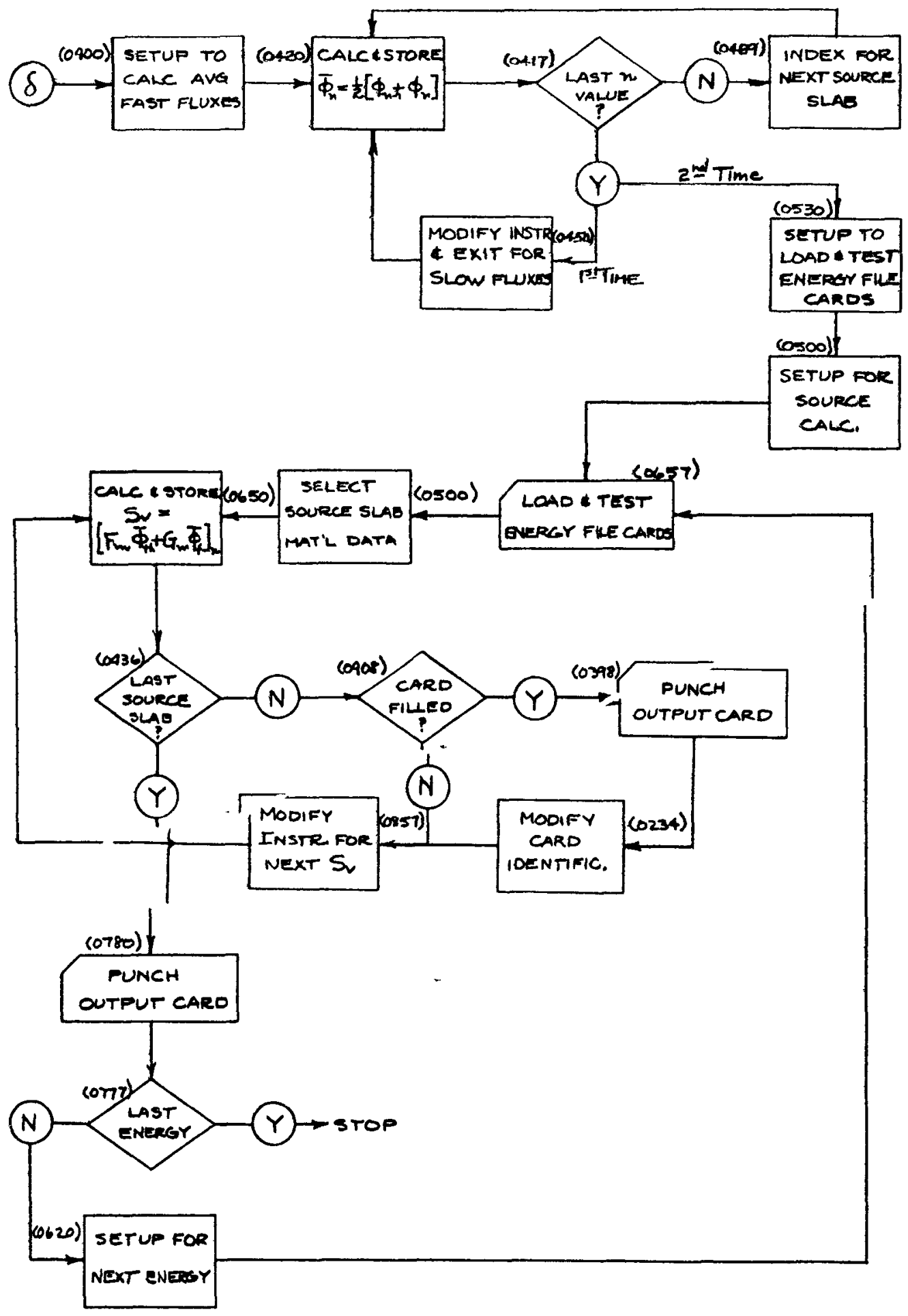

Flow Chart For Program 652 

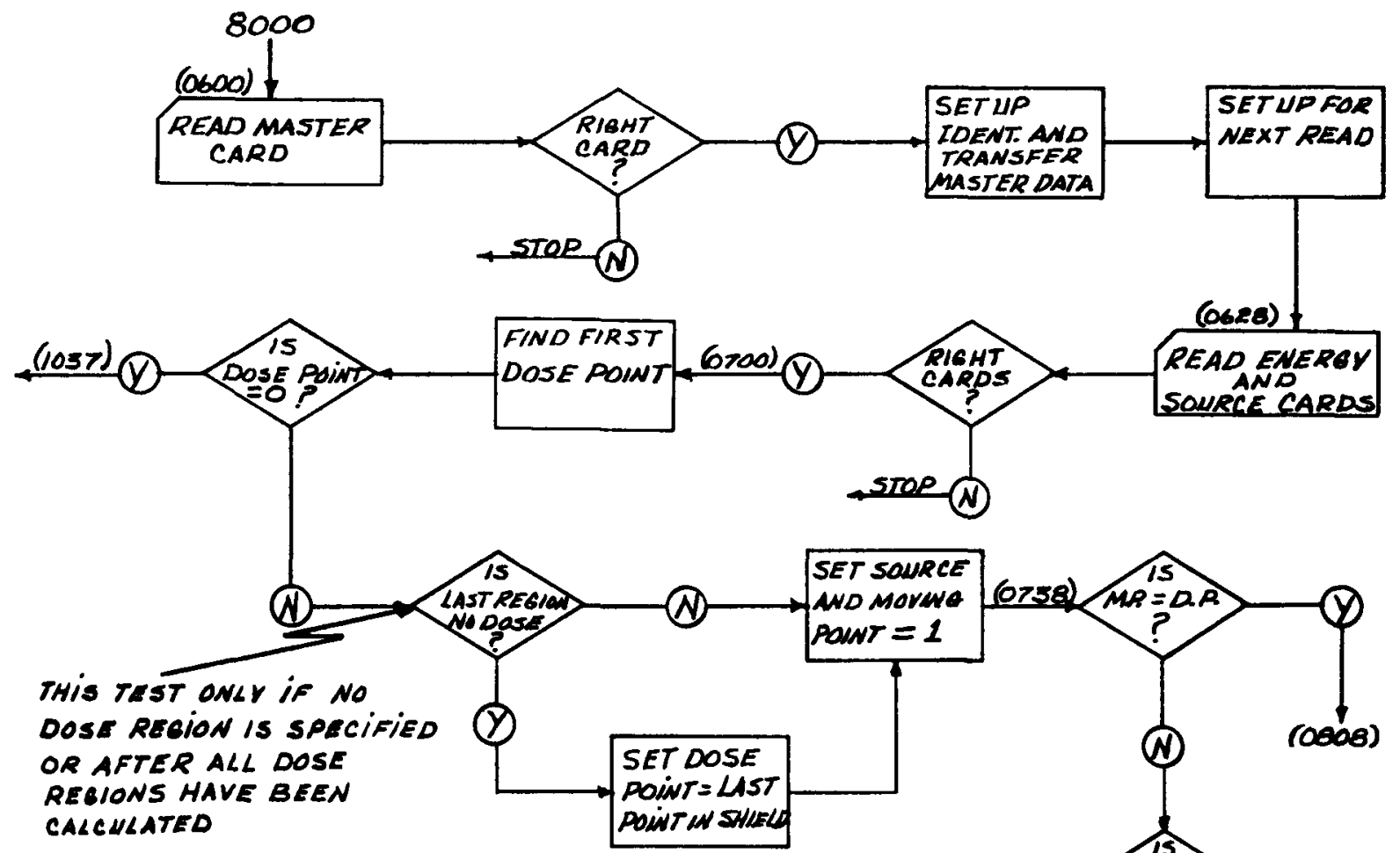

RECIOA CALGULATED
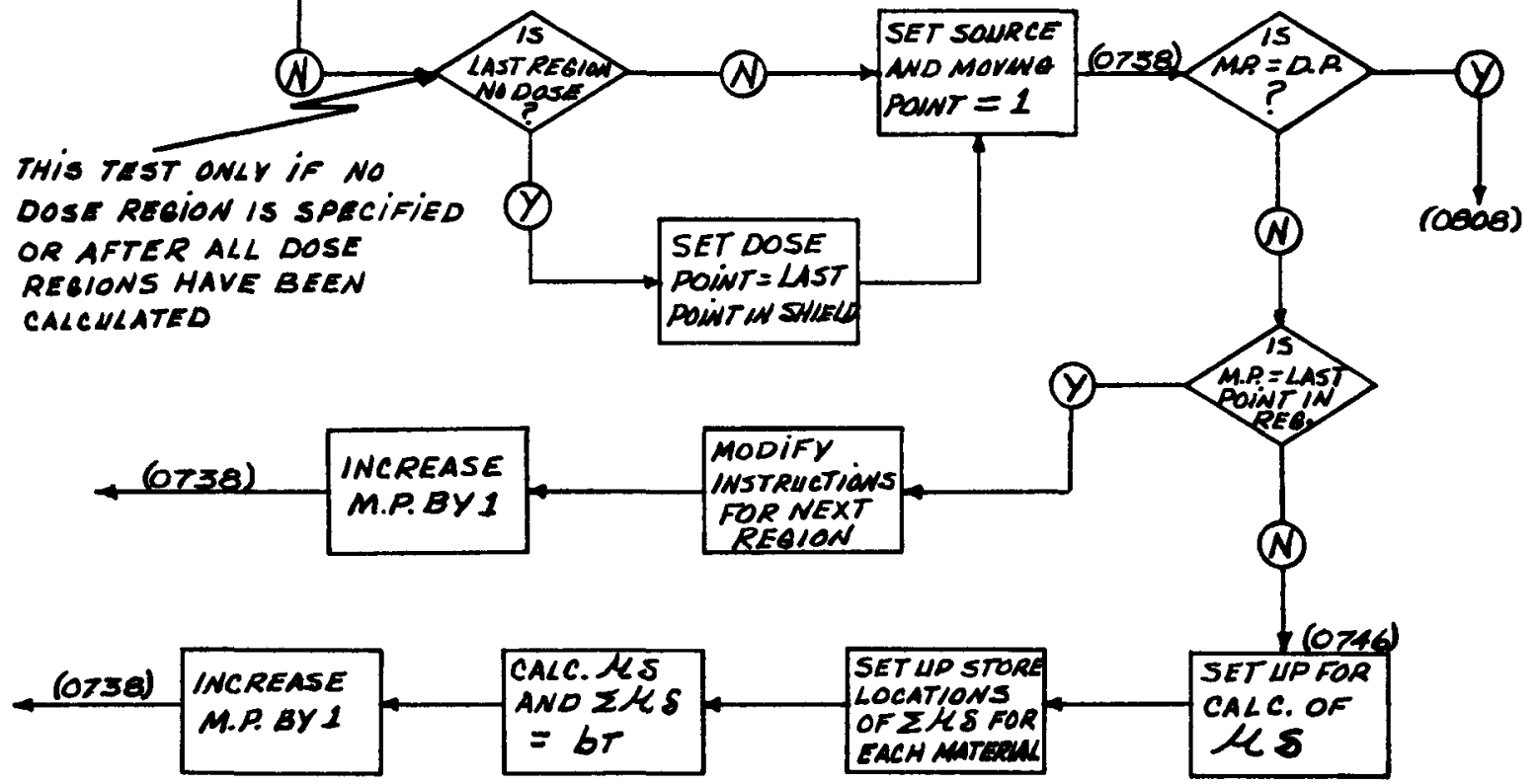

Flow Chart For Program 653 


\section{APPENDIX E}

ENTRY FOR CALCULATION OF $D_{2}=D_{1}=\frac{5 n}{2 \mathcal{H}_{5}}\left[1-E_{2}\left(\mathcal{L}_{s} \Delta_{s}\right)\right]$

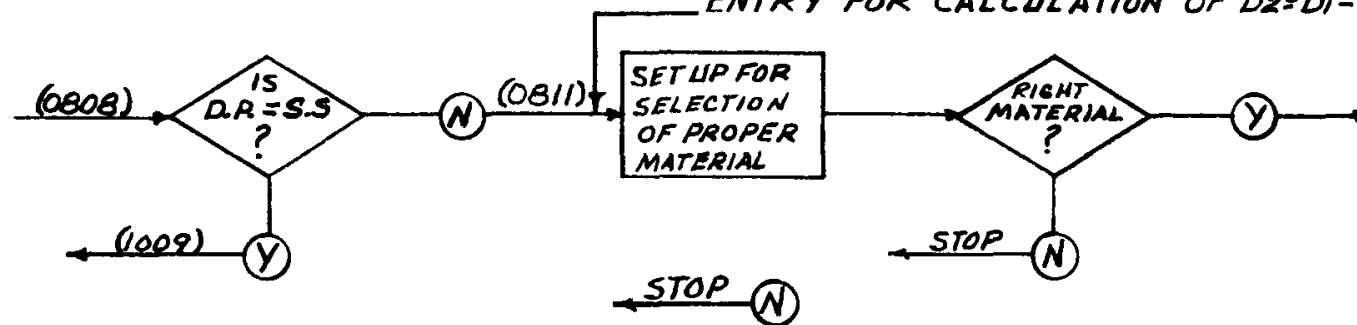

SETUPTO CALCLLATE Hs $\Delta s$
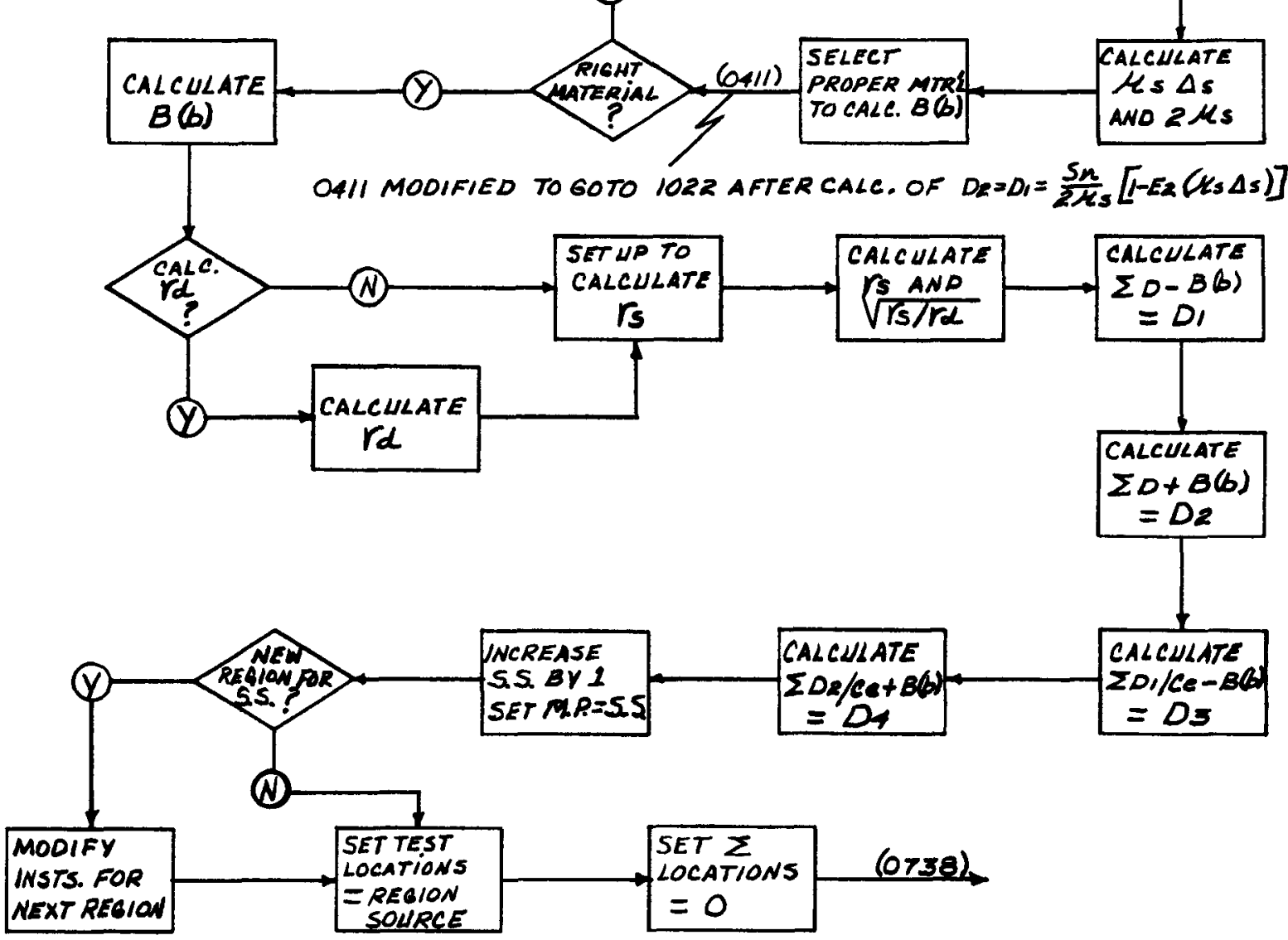

Flow Chart For Program 653 

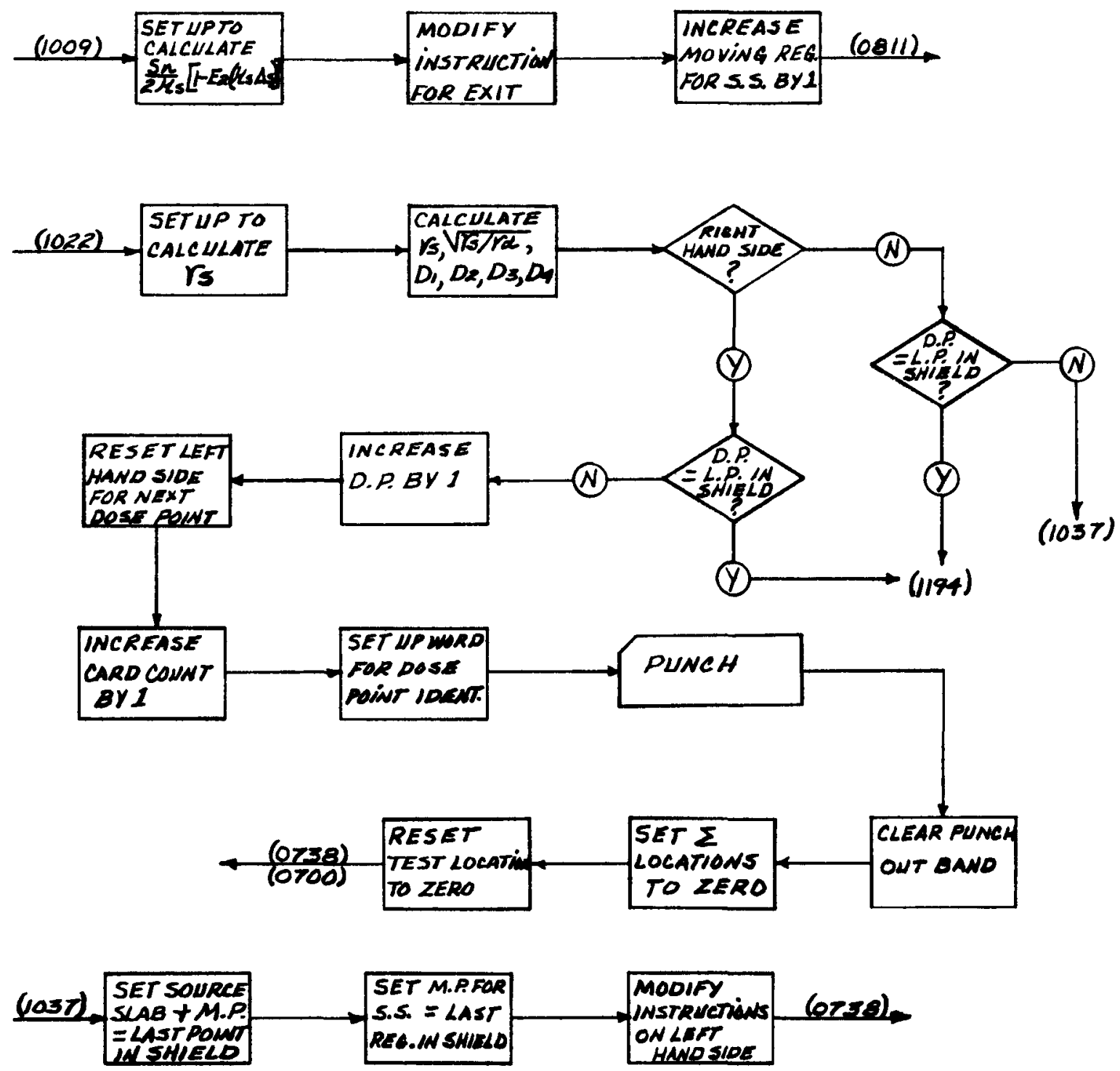

Flow Chart For Program 653 


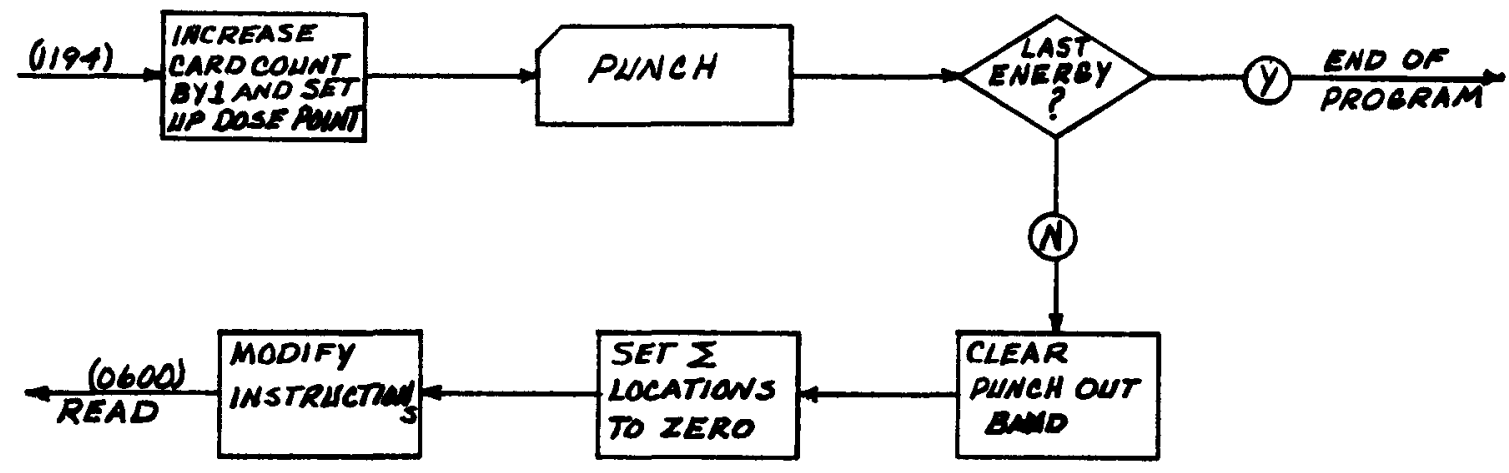

Flow Chart For Program 653

8,1,

$3 x_{5}$ 


\section{APPENDIX E}
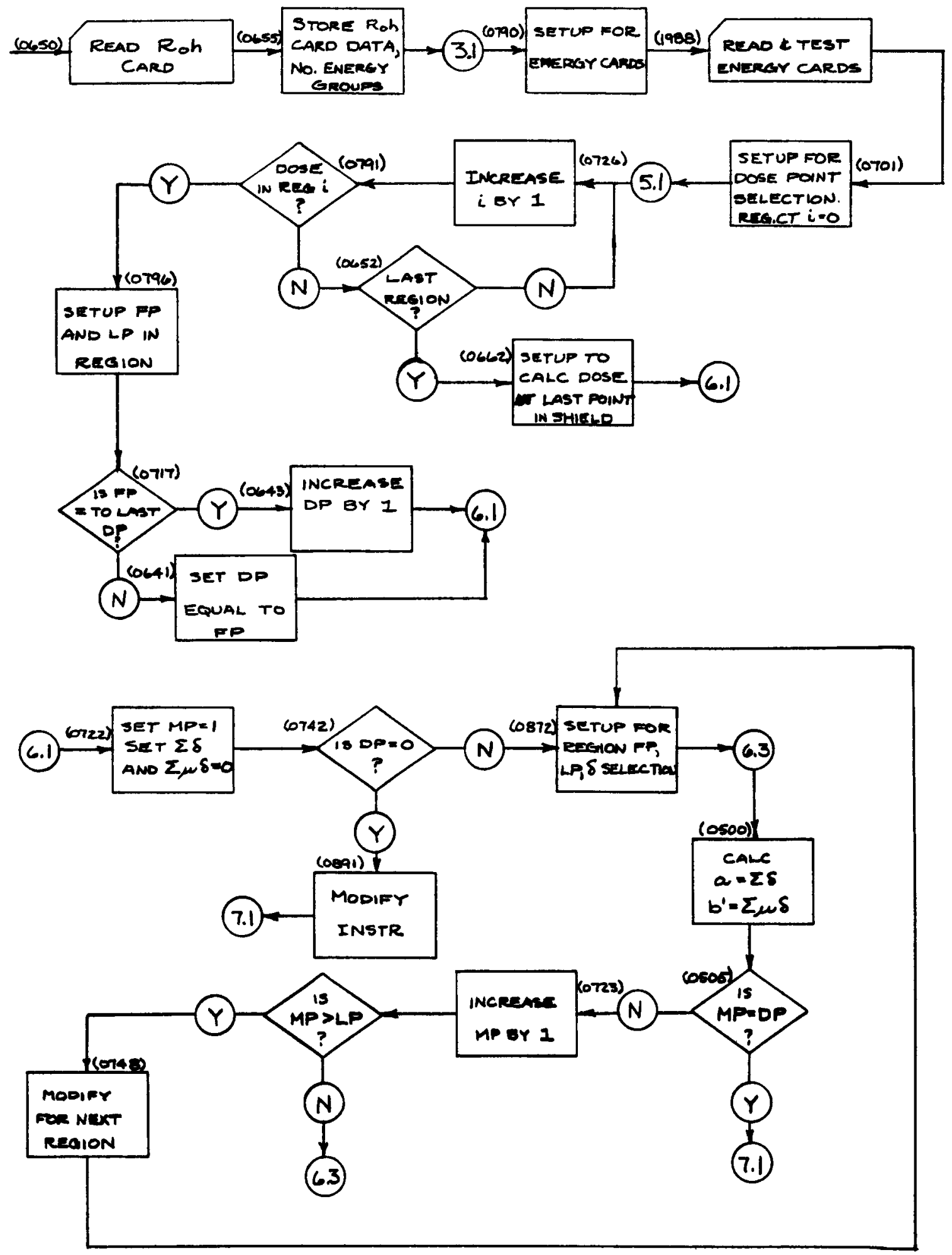

Flow Chart For Program 654 


\section{APPENDIX E}
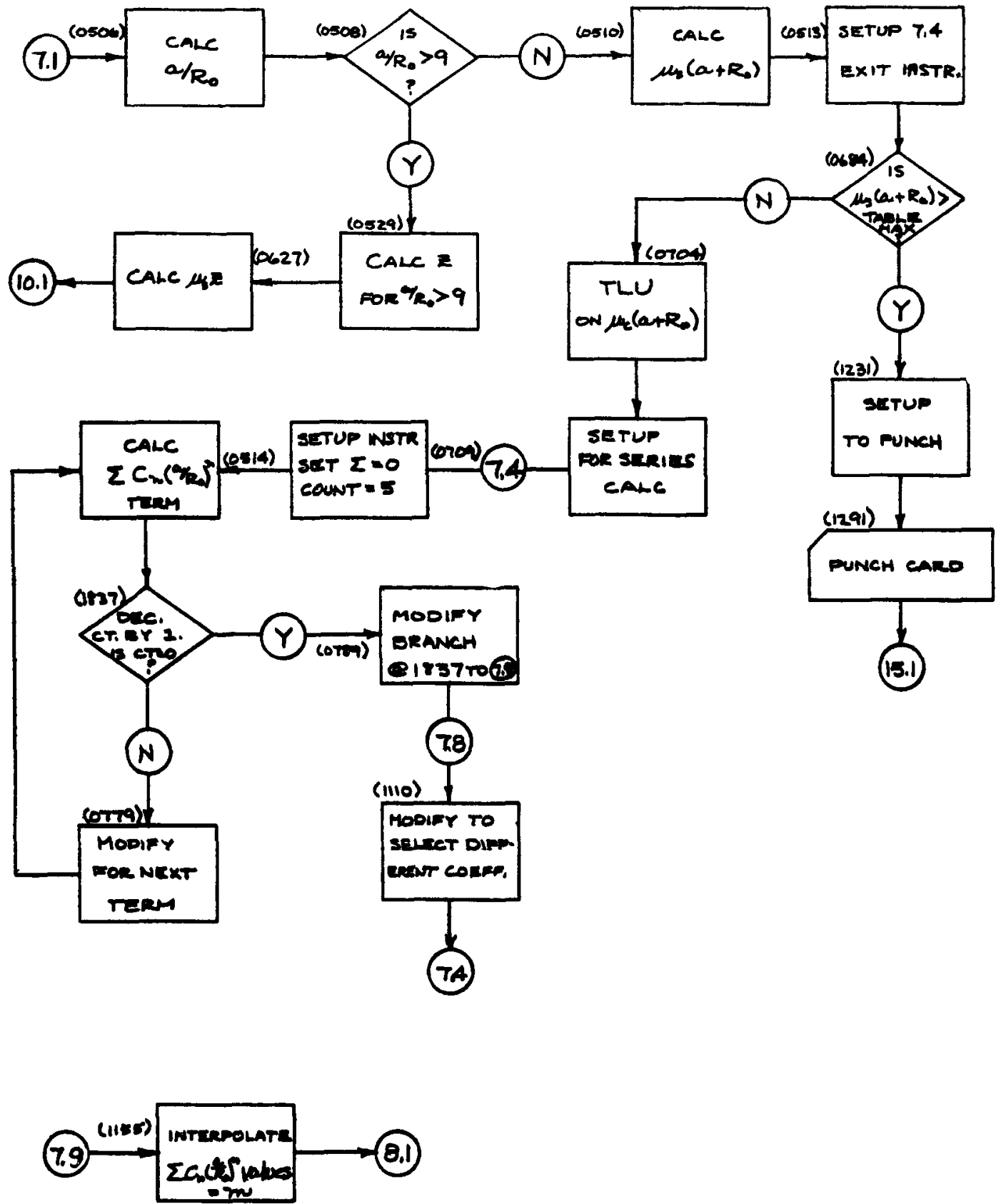

Flow Chart For Program 654 

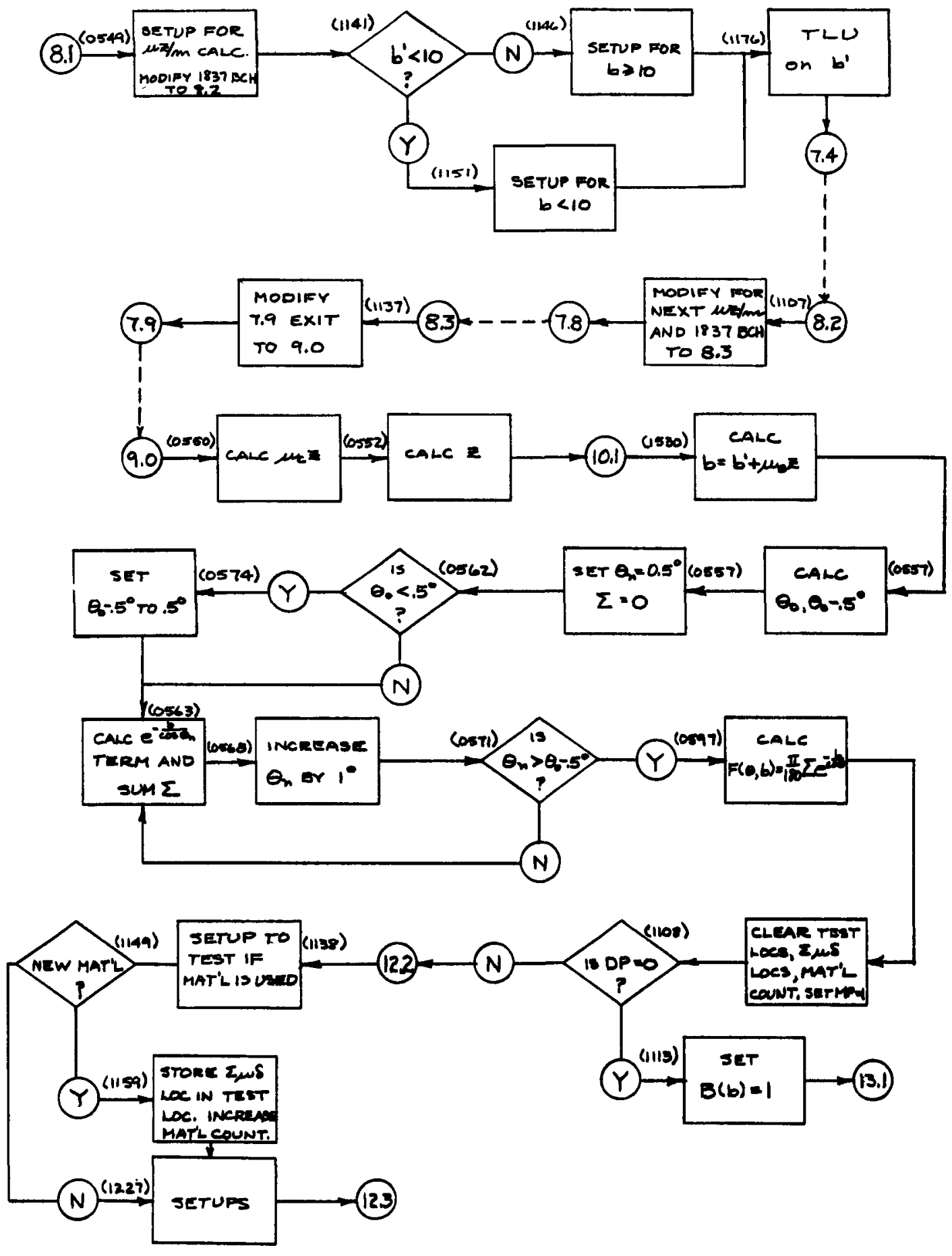

Flow Chart For Program 654 


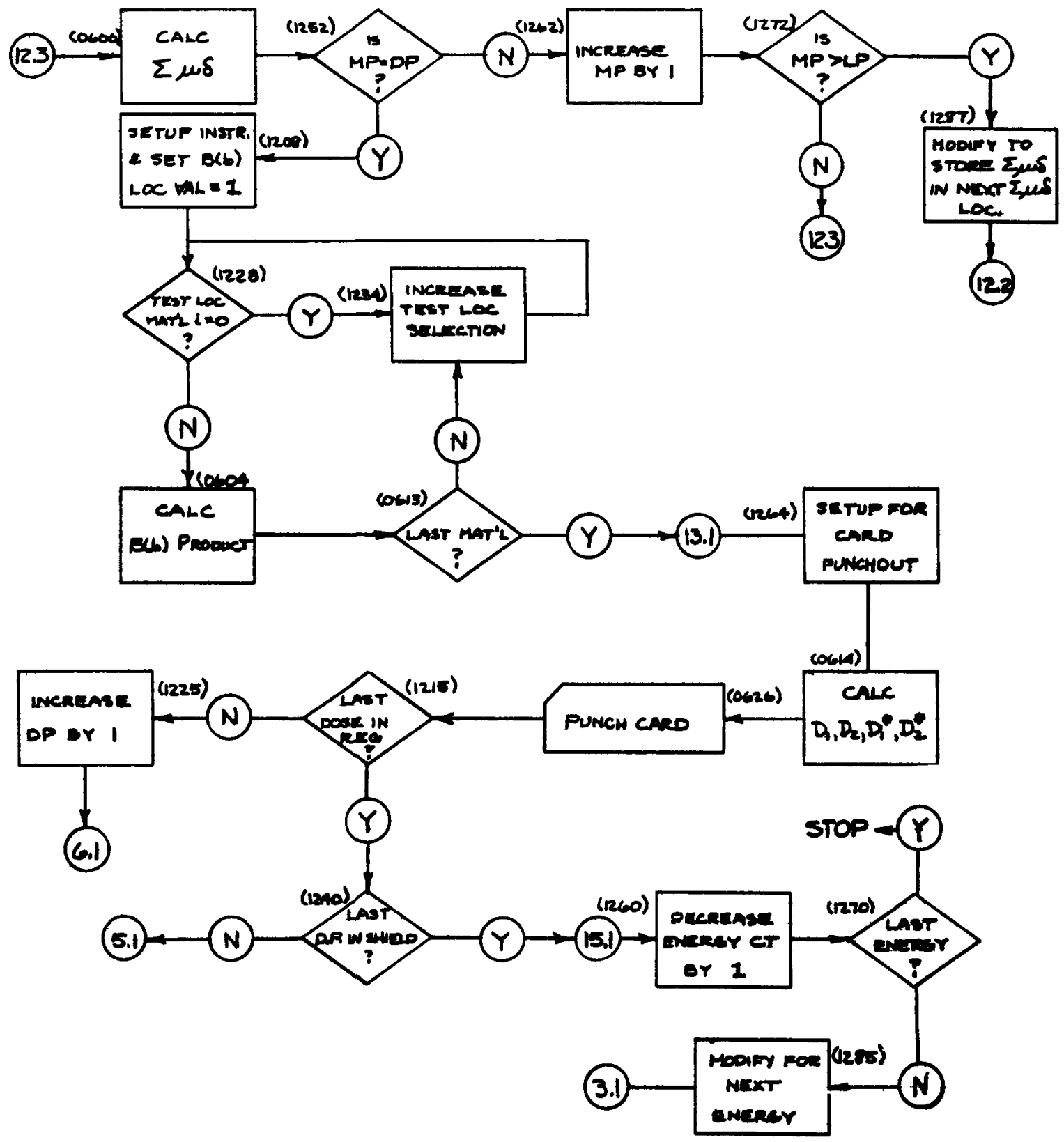

Flow Chart For Program 654 